\title{
A dança-de-ombros de Mário de Andrade: surupango da vingança
}

Vagner Camilo

\section{Resumo}

Este artigo analisa "Danças" (1924), de Mário de Andrade, e a reflexão que o poeta desenvolveu sobre as dimensões estética e ética implicadas nos versos, especialmente nas cartas endereçadas aos amigos, que respondem pela primeira recepção do poema. A mudança de atitude em relação a seu próprio poema é examinada em consonância com as dúvidas e conflitos que assolarão poetas e artistas na transição dos anos 1920 e 1930.

Palavras-chave: Mário de Andrade, poesia, "Danças", "Reconhecimento de Nêmesis", Modernismo. 
Em resenha de 1942 publicada na revista Clima, Antonio Candido propunha uma famigerada triagem da obra poética de Mário de Andrade em quatro grandes vertentes, que compreendiam o poeta folclórico de Clã do jaboti; o poeta do cotidiano, de Pauliceia desvairada, Losango Cáqui e em parte de Remate de males; o poeta de si mesmo, ao qual se alinha com frequência, em termos meio drummondianos, o poeta do eu mais o mundo, ainda em Remate de males, A costela do Grãcão e o Livro azul; somando-se, por fim, o criador de poéticas (CANDIDO, 1942, p. 72). Como nota Lafetá, não foi dado ao resenhista conhecer, à época, uma última faceta do poeta que se revelaria nos anos imediatamente seguintes: a do poeta político, que despontaria no momento em que a "luta ideológica se agudiza, comunistas e fascistas se organizam e cresce o grau de consciência de classe", levando o poeta a compor o Carro da miséria, Lira paulistana e Café (LAFETÁ, 1986, p. 7).

Do conjunto dessa extensa produção, interessa-me propor um brevíssimo comentário sobre um dos mais conhecidos poemas de Remate de males (1930), livro instalado justamente no meio desse itinerário poético. Por isso, Candido reitera, em outro momento, que o livro ocupa uma posição-chave, "porque representa a passagem da poesia mais exterior dos primeiros tempos de luta modernista para a poesia mais interior da última fase". (CANDIDO, 1993, p. 256)

Sabe-se que o belo título do volume é um topônimo emprestado a um vilarejo amazônico na fronteira do Brasil com o Peru, sobre o qual Mario ouvira falar durante a viagem à região norte do país, pela boca de um nativo que, segundo informa o turista aprendiz, tinha acabado de ser vítima de uma congestão cerebral... $\mathrm{O}$ achado marioandradino, ao converter toda a sugestão metafórica do topônimo em síntese da subjetividade lírica, da poética ou do contexto mais imediato a que remete o livro, seria seguido depois, como também se sabe, pelo Drummond de Brejo das almas e, inspirado em ambos, pelo Cabral de Pedra do sono.

Sobre a especificidade do livro de 1930, já se notou que ele reverbera uma inflexão significativa da fase combativa ou heroica do modernismo, ao promover uma espécie de balanço das experiências dos anos 1920, condensando-lhe o espírito revolucionário na passagem para os anos 1930 que, além da rotinização das experimentações vanguardistas, 
1 Já examinei essas polarizações, tal como elas repercutiram na poesia do período, notadamente em Drummond, verdadeiro sismógrafo poético da época, aproximando-o ainda de Bandeira e Augusto Meyer, partindo do observado pelo próprio Mário no conehcido ensaio sobre "A poesia de 1930" ao tratar do "voumemborismo" bandeiriano como expressão de um estado de espírito generalizado entre os poetas do período, de que "Danças" seria também um testemunho. Ver Vagner Camilo. “No atoleiro da indecisão: Brejo das almas e as polarizações ideológicas nos anos 30". In: Benjamin Abdala Junior e Salete de Almeida Cara. (org.). Moderno de nascença: figurações críticas do Brasil. São Paulo: Boitempo, 2006. viriam marcados pelos choques e polarizações ideológicas de intelectuais e artistas, de que a literatura do período deixou tão grandes registros ${ }^{1}$. Trata-se, em suma, da repisada transição do projeto estético para o ideológico, nos consabidos termos do mesmo Lafetá (LAFETÁ, 1974).

Configurando mais especificamente o contexto de inserção do livro, nota o autor de Figuração da intimidade que Remate de males, abrindo um período novo da história republicana, é sintomático da liquidação geral de que procede e revela

notável simetria com o ímpeto de mudança-de-rumos que gera a revolução. Não é o único livro a anunciar o fim de uma etapa e o início de outra: do mesmo ano são Libertinagem, de Manuel Bandeira, Alguma Poesia, de Drummond, Pássaro cego, de Schmidt e Poemas, de Murilo Mendes. (Logo depois Mário de Andrade os discutiria no ensaio "A poesia em 1930"). São "sinais", todos eles. E Tristão de Ataíde, a propósito do tom dos poemas de Schmidt, chega a afirmar: "Sua gravidade, sua tristeza, sua inquietação, sua renúncia ao frívolo, ao superficial, ao pitoresco, seus apelos à vida calma, sua vontade de partir, seu messianismo - tudo se ilumina à luz da grande tragédia que se elaborava misteriosamente no seio mais oculto de nossa pátria e de que muitos descuidaram, atraídos pela calma das aparências".

Nessas palavras do crítico vai, naturalmente, um ataque ao que ele considerava o "sibaritismo", a frivolidade da literatura modernista. Mas, isto à parte, de alguma forma ele acertou: a literatura posterior à Revolução de Trinta tomará um tom muito mais grave e pesado, muito mais "responsável" e "sério". (LAFETÁ, 1986, p. 28-29)

Seguindo ainda com o crítico, ele chama a atenção para a diversidade de temas, formas e motivos de Remate de males, que tem um poema como "Danças", concebido ainda

no melhor estilo de combate de vanguarda, fragmentário, destruidor; tem o "Tempo de Maria" (1926), construtivo, pitoresco, saboroso e brasileiro como os textos impregnados pelo sentimento "possivelmente pau-brasil"; e tem experiências finais da década, quando o Modernismo abandona as contingências e a estética do choque, e reflui para uma meditação mais interiorizada: os "Poemas da negra" (1929) e os "Poemas da amiga" (1929-1930), que prenunciam a produção modernista madura e equilibrada dos anos trinta. (LAFETÁ, 1986, p. 28) 
Quanto ao alinhamento do livro de 1930 proposto por Lafetá, ao lado de Libertinagem e Alguma poesia, gostaria de sugerir que Remate de males também revela afinidade com Brejo das almas, não só pela apropriação lírica do topônimo, mas pelo que exprime de estado de espírito comum, reinante entre os poetas do período.

Examinando a confluência entre poesia e música em Mário de Andrade, Cristiane de Souza nota que a riqueza melódica da poesia cantada em Clã do Jabuti vai se tornar mais complexa no livro de 1930, em que o eu marioandradino se reconhece como voz plural ("Eu sou trezentos, sou trezentos-e-cincoenta..."), acolhendo em si, contraditoriamente, a diversidade antes encontrada na música dissonante da metrópole paulistana (em Pauliceia desvairada) e nos tons folclóricos e populares do interior do Brasil. Pensando no que ainda observa a intérprete sobre a estrutura das danças dramáticas que molda os poemas de Mário como forma de encenação dos dilemas do eu (SOUZA, 2009, p. 6), interessa-me aqui, dentre a diversidade de tendências do livro de 1930, considerar o poema supostamente herdeiro da fase combativa: "Danças" (1924).

Embora tributário das experimentações formais e da atitude irreverente dos anos 1920, o poema e a discussão que o cercou desde sempre traduzem as inquietações que marcariam a transição para a década seguinte, o que se evidencia inclusive na primeira recepção e na destinação de "Danças" em relação ao restante da obra e em vista da mudança de atitude do próprio poeta face a tal poema.

Dentre os processos formais que o caracterizam, destacam-se a alta incidência de enumerações, a riqueza de ritmos, o dinamismo nas disposições gráficas, estratégicas - e claramente miméticas, como os demais procedimentos retóricos empregados - das palavras na página, além do manejo do verso livre, ao que se somam as personificações ou prosopopeias, as aliterações, assonâncias e onomatopeias. É assim que música e movimento confluem em "danças", empregadas no plural para caracterizar a diversidade de referentes que elas metaforizam: é, sobretudo, a atitude do eu lírico, mas também dos demais homens e de setores da vida nacional, social e econômica. Pasini nota que o poema sintetiza o "moto lírico" vertiginoso de várias tendências modernistas e realiza as leis ou preceitos estéticos propostos em A escrava que não é Isaura (substituição da 
2 Cito o poema, que teve duas versões (a de 1924, na revista Estética, e a de 1930, em Remate de males) com base no texto estabelecido para as Poesias completas (Rio de Janeiro: Nova Fronteira, 2013, v.1, p. 296-312) de Mário de Andrade, cuidadosamente anotadas por Tatiana Longo Figueiredo e Telê Ancona Lopez. ordem intelectual pela subconsciente, polimorfismo, rapidez e síntese) (PASINI, 2011, p. 90). Creio, talvez, seja possível também reconhecer nos versos outros aspectos reivindicados no Prefácio interessantíssimo, a exemplo das discussões de Mário a respeito de melodia e harmonia transpostas para a poesia.

Se na abertura do poema, as "Danças" ajudam a personificar a ação dos fenômenos naturais que se projetam intensamente nas ruas da cidade e notadamente no espaço de confluência e socialização queé a praça ("Dança a poeira no vendaval./Raios solares balançam na poeira./ Calor saltita pela praça..."2), logo em seguida passam a compreender a dinâmica da urbe, com a personificação de ícones da modernidade e da técnica:

$$
\begin{gathered}
\text { [...] pressa } \\
\text { apertos } \\
\text { automóveis } \\
\text { bamboleios } \\
\text { Pinchos ariscos de gritos } \\
\text { Bondes sapateando nos trilhos... }
\end{gathered}
$$

As danças podem caracterizar, também, a movimentação da vida social e mundana da cidade, indo da ebulição do grand monde que se diverte nas dependências elegantes do recéminaugurado Hotel Esplanada (do qual Oswald pretendia ser o trovador, em conhecida balada), até os subúrbios e pensões onde o eu busca refúgio para suas aventuras:

[...] O Esplanada grugrulha.

Todos os homens vão no cinema.

Lindas mulheres nos camarotes.

Leves mulheres a passar...

Não frequento cafés-concertos, Mas tenho as minhas aventuras...

Desventurados os coiós!

A vida é farta.

O mundo é grande.

Tem muito canto onde esconder! Subúrbios casas

pensões

táxis... 
As danças podem também se referir à principal atividade econômica do país, cujo sobe-e-desce é associado ao elevador, quem sabe do próprio hotel, que foi o primeiro a contar com esse outro signo de conforto e modernidade:

O elevador subiu aos céus, ao nono andar,

O elevador desce ao subsolo,

Termômetro das ambições.

$O$ açúcar sobe.

O café sobe.

Os fazendeiros vêm do lar.

Eu danço.

E, ainda, em termos de vida e interesse econômicos, temos:

Trusts de cana, trusts de arroz, Açambarcadores de feijão-virado...

Ligado ao interesse econômico, as danças metaforizam, em outros versos, o movimento financeiro, refletido na exploração e viravolta da bolsa de valores, letras de câmbio e ouro:

A Bolsa revira.

Reviram-se as bolsas.

As letras entram.

Os ouros saem...

\section{Corrida}

Tombos

Vitórias

Delírios

Banquetes

Orquestras...

Os homens dançam ...

Danço também.

A generalização das danças como metáfora para o conjunto da vida social chega a ser expressa ou reiterada em mais de um momento, em versos como estes:

Tudo é subir.

Tudo é descer. 
Tudo é dançar.

[...]

Tudo é girar, tudo é rodar.

A metáfora se aplica, inclusive, à própria língua, ao falar popular brasileiro, com a dança dos pronomes pessoais (e a "infração" básica em relação à norma do português) de que se ocupa toda a parte III do poema, e que sabemos ser desde sempre tópica central ao projeto de língua nacional do autor de "O baile dos pronomes" (ANDRADE, 2002, p. 26974). E é justamente o jogo do pronomes pessoais que ajuda a disseminar a metáfora para os demais homens e setores da vida nacional, social e econômica.

Em se tratando de linguagem, a metáfora em questão é empregada para caracterizar o próprio trabalho literário. É assim que, depois de exibir sua erudição pela evocação das leituras estrangeiras diletas (não só de diferentes línguas, algumas lidas no original, mas também transitando da ficção a outras áreas como a psicanálise) e pela menção às revistas do Brasil, que atesta o quanto ele se mostra atualizado e antenado com o que se produz aqui, o eu poético revela sua destreza na prática de formas poéticas tradicionais, mas não sem uma boa dose de desprezo, como bem atestam o ditirambo "enramado" (sugerindo algo de ornamental), o madrigal "guspido" e o dar de ombros final logo depois de composto.

Leio em vernáculo Tristam Shandy.

Conheço Freud e Dostoievsky.

Compro as revistas do Brasil.

$\mathrm{E}$

Principalmente

Sei enramar meu ditirambo,

Sei guspir um madrigal!

Depois dou de ombros.

Meus ombros dançam.

Ainda na esfera do indivíduo e mesmo da criação poética, a dança parece servir como resposta à idealização amorosa, rompendo com a convenção neoplatonizante legada pelo romantismo, que o próprio Mario trataria de examinar no 
polêmico estudo sobre Álvares de Azevedo e a psicologia dos nossos românticos ("Amor e medo"). Investe, assim, contra a imagem da virgem etérea e contra uma das figurações paradigmáticas da lírica azevediana, qual seja a visão da jovem dormindo no leito (o "complexo de bela adormecida" que ele atribui aos românticos no seu suposto e discutível "medo de amar"), enquanto o eu poético vela o sono da amada e entregase a atitude contemplativa de que resulta a poesia. $\mathrm{O}$ eu lírico de "Danças", além de qualificar essa atitude como tola, vai propor a movimentação da dança como resposta ao tédio resultante do imobilismo contemplativo. É o que se observa na parte IV do poema, no diálogo travado entre o eu e a jovem que, em vez de todas as denominações sublimes e idealizantes que o romantismo empregou (donzela, virgem, anjo...), é tratada simplesmente por "filha". A atitude absolutamente irônica em relação à paródia da cena amorosa convencional se deixa depreender ainda das reações do eu e da moça. Ora, diferentemente do modelo parodiado, a ordem de sentimento que produz a contemplação da jovem que vai cedo e contrariada para o leito, e que efetivamente não consegue conciliar o sono é de aborrecimento, de um lado e de outro. Distintamente também do modelo original, a imagem dessublimada da jovem encolhida na cama larga, com os cabelos suados e esperdiçados, e as mãos tamborilando, longe do repouso, aponta para a inquietação, visível ainda mais no corpo que treme e vibra. Irritação essa não só com a contemplação, mas igualmente com as indagações que lhe dirige o poeta. A pergunta reiteirada "Devo-te esconder o meu sorriso?" - reforça a intenção cômicoparódica do episódio, até que, por fim, o poeta propõe a dança como solução para tamanha inquietude e impossibilidade de conciliar o sono:

14 horas.

Filha, tua vais dormir.

Eu te contemplo aborrecido.

Que fazes estreita na cama tão larga?

Por que te encolhes assim?

Teus cabelos suados se esperdiçam.

Tuas mãos aziagas tamborilam.

Teu corpo estreito treme vibra... 
- Poeta, me deixe dormir! ${ }^{3}$

Eu te contemplo aborrecido...

Devo esconder-te o meu sorriso?...

Já sei por que o sono não chega,

Filha, começas a dançar...

Teu corpo todo se enrodilha

estremece

sacode

bate

lata

seco

... heque! heque!...

quebra

queima

reina

dança

sangue

gosma...

Teus lábios dançam:

$$
\text { - Por piedade! }
$$

Não é domingo nem dia-santo!

Filha, tu danças para dormir!

Tosses até que não podes mais!

Devo esconder-te o meu sorriso?...

Na sequência do poema, rompendo com o ambiente fechado e claustrofóbico da alcova, frequente na convenção romântica, o eu sai à rua, onde é o ar leve e livre que agora dança, assim como as rosas da capital paulista, caracterizada como um grande jardim e rosal:

3 As organizadoras das poesias completas registram uma variante desse verso na versão do poema para a revista Estética, em que a jovem nomeia o eu lírico com o próprio nome do poeta: “- Mário, deixa-me dormir!".

Aquele quarto me sufoca,

Prefiro ar livre,

Não voltarei.

Ar livre, ar leve que dança, dança!

Dançam as rosas nos rosais!

São flores vermelhas 
São botões perfeitos

São rosas abertas, gritos de prazer!

São Paulo é um rosal!

São Paulo é um jardim!

Morena, tem pena,

Tem pena de mim

Vale, por último, insistir no fato de a imagem das danças definir sobretudo essa dança-de-ombros do eu lírico, numa atitude típica de irreverência, de não-me-importismo, que pode sim, em parte, ser tributária da postura iconoclasta, da irreverência e do desejo, em suma, de épater a estreiteza da moral burguesa reinante, atitude que sabemos característica da fase heroica do Modernismo. É o que se vê em versos como:

A moral não é roupa diária!

Sou bom só nos domingos e dias-santos!

Só nas meias o dia-santo é quotidiano!

[...]

O bem e o mal, que coisas sérias!

[...]

Sou partidário da desombra nacional

Ainda como herança da primeira fase, a dança serve, pela ênfase no corpo e na alegria [o riso claro dos modernos, como diria Candido], como forma de reação à seriedade e à abstração do trabalho intelectual ou do próprio esforço reflexivo:

Eu danço!

Mãos e pés, músculos cérebro...

Muito de indústria me fiz careca,

Dei um salão aos meus pensamentos!

Tudo gira,

Tudo vira,

Tudo salta,

Samba,

Valsa,

Canta,

Ri!

[...]

EU DANÇO! 
Eu danço manso, muito manso,

Não canso e danço,

Danço e venço,

Manipanço...

Só não penso...

Quando nasci eu não pensava e era feliz...

Quando nasci eu já dançava,

Dançava a dança da criança,

Surupango da vingança...

A irreverência parece, todavia, trazer em germe a autocrítica que vai despontar cada vez mais no correr dos anos. Ela se deixa entrever, talvez, no avesso da expressão exclamativa com que se abre o poema, logo convertida em indagação:

Quem dirá que não vivo satisfeito! Eu danço!

[...]

Quem foi que disse que não vivo satisfeito?

EU DANÇO!

A afirmação peremptória destacada em caixa alta mal encobre o fato de se tratar, na verdade, da denegação do real sentimento que assola o eu. Esse sentimento corresponde à atitude oscilante do eu lírico, partilhada à época por outros poetas como Drummond e a indecisão de Brejo das almas (cf. Camilo, 2006), e formulada aqui expressamente na penúltima parte do poema, por meio da imagem do rio da Dúvida e da vitória-régia que, apesar do poder de sugestão do nome, "oscila balouçante nas águas indecisas" no momento em que o eu lírico se reporta à realidade mais profunda e desconhecida das "terras incultas":

\section{VIII}

Há terras incultas além muito longe ...

Há bichos terríveis nas terras incultas ...

Há pássaros lindos nos jequitibás ...

O dia ora é claro, ora é escuro...

Zumbidos de abelhas fabricando mel... 
Ora os bichos urram,

Ora as aves cantam,

Ora é a flor que abrolha,

Ora a árvore cai ...

O céu se escurece. É a tormenta ...

Dançam coriscos no céu.

Relâmpagos

trovões

um samba hediondo,

um candomblé ...

As caiporas galopam nas ancas das antas...

Aranhas formigas sacis e Jaci ...

O rio da Dúvida passa a dançar ...

A vitória-régia oscila balouçante nas águas indecisas ...

Ha terras incultas além ...

Mas quem que as visitou?

Ninguém.

A confusão é enorme!...

Filha, tu sabes ... que hei-de fazer!

Tudo é quadrilha!

Me ponho a dançar!

Ligada à evocação da dúvida, temos a transfiguração do cenário natural, com o prenúncio e desencadear da tormenta (e agora são os coriscos que dançam no céu...). Vale ainda lembrar aqui a parte suprimida do poema que consta da versão publicada em Estética para atestar o conflito ou "confusão" que atordoava o eu lírico dividido entre as novidades estéticas que chegavam de fora (ligadas ainda à agenda dos anos 1920) e a consciência de um país arcaico completamente desconhecido, fazendo, assim, despontar certas inquietações políticas que viriam, de fato, a se intensificar nos anos 1930:

Infelizmente há também os tratados políticos. O Brasil se obstina em cumpri-los. País idealista! Rondon passou rasgando a terra virgem. O telégrafo corta agora as paisagens incultas, trazendo notícias europaicas: 'Inventa- 
se o dadaísmo'; Aragon escreve Anicet; 'Der Sturm inebria a Alemanha'; 'Em Moscovia o teatro popular é cubista'; ‘Ultraísmo em Madrid'... Chassé! En avant! En arrière! Balancé! Tour!... Em São Paulo sabe-se vagamente que há terras incultas ao longe. Mas quem as visitou? Ninguém. A confusão é enorme. (ANDRADE, 2013, p. 310)

Essa mudança de atitude encenada nos versos pode ser palmilhada em algumas das cartas de Mário de Andrade, que tratam inclusive da primeira recepção do livro - quando o poema circulou entre amigos, dançando de mão em mão - e, em seguida, de sua destinação mais ampla. Está visto que essa mudança em relação ao poema diz respeito fundamentalmente à atitude (a)moral que ele implica. Vejamos algumas das várias cartas.

Mário de Andrade dá notícia da composição de "Danças", pela primeira vez, em carta endereçada a Manuel Bandeira de 15 de novembro de 1923, ironizando inclusive com a data... “Viva a República?" Destaca aí, em particular, o "cinismo filosófico" dos versos:

Meu querido Manuel, perdoa a longa demora. Mas não me perco em explicações. Retardaria o que tenho a dizer. Acabei um poema. "Danças". Se encontrares o Guilherme [de Almeida] aí no Rio, poderás ler o poema que com ele está a única cópia que fiz. Prego agora a filosofia do dar-de-ombros. Tem esse versinho que resume todo o meu atual cinismo filosófico: São inimigos, / São morfinômanos, / Virgens e honestos, / Crápulas vis. / Saúdo a todos. / Ninguém me estima. / Dançam meus ombros. / Eu sou feliz. (ANDRADE \& BANDEIRA, 2000, p. 104)

Essa felicidade que o eu lírico declara nos versos acima será posta em questão pelo poeta em carta enviada ao mesmo Bandeira dois anos depois, ao comentar o equívoco das concepções filosóficas de Graça Aranha e a suposta alegria que este reconhece em "Danças":

São Paulo, 7 de maio de 1925. [...]

Graça [Aranha] querendo fazer do brasileiro um tipão alegre por... teoria filosófica e integração no Todo Infinito com uma incompreensão inteirinha do homem brasileiro que ele não observou, contrariando a psicologia natural desse homem, fazendo da alegria um preconceito a ponto de ver alegria nas minhas "Danças" tão tristes e tão doloridas, qual! (ANDRADE \& BANDEIRA, 2000, p. 206) 
4 Essa Perpétua Alegria é, para Graça Aranha, resultante da transformação de todas as emoções (prazer ou dor, tristeza e melancolia) em beleza, da existência pautada pelo "jogo maravilhoso" de quem sabe ser a "consciência uma ilusão, que não tardará a voltar à inconsciência universal", da aceitação resignada dessa "fatalidade cósmica" que abisma a todos no Nada; da "profunda e mística união dos sentidos e das emoções, dos espíritos e dos corpos", "sublime fusão do Amor" realizando "a universal unidade", sentindo-se "um com o Universo infinito" e encontrando "o repouso na sua absorção no cosmos [...] Beatus quia in natura unus".

5 SãoPaulo, 21/02/1926. [...] "Infelizmente não posso tratar de minhas obras porque os trabalhos de precisão prática são enormes agora. É pena porque o estado de excitação em que estou devia ser frutífero como já foi na ocasião de "Danças" e da Escrava." (Devo a rastreamento das menções às "Danças" na correspondência de Mario a Marcos Antonio de Moraes, a quem registro aqui meus agradecimentos.)
Sabe-se o quanto irritava a Mário a teoria filosófica defendida por Graça Aranha em A estética da vida sobre a Perpétua Alegria ${ }^{4}$, que ele viria a atacar de frente em uma das Crônicas de Belazarte (América brasileira, Rio de Janeiro, jan. de 1924). O que importa, todavia, notar no excerto acima é como Mario contesta a suposição de uma alegria subjacente às "Danças" que, a seu ver, encerram dor e tristeza! É bem verdade que, em outra carta, Mario falaria do "estado de excitação" de que "frutificou" o poema, mas isso nada tem a ver com a hipótese de que ele encerra a alegria que lhe atribui Graça Aranha.

E Mário trataria de insistir no equívoco da concepção de Graça, numa famosa carta enviada a Drummond, não datada, mas certamente de fins de 1924, na qual afirma que, em vez do ceticismo, é o cinismo que define o fundamento filosófico de "Danças" - não mais o ceticismo, mas o cinismo:

Talvez você veja contradição entre a minha filosofia das "Danças" e todo este ataque ao ceticismo. Não há contradição, Drummond. Aliás, nem é bom ceticismo a filosofia que ressuma das "Danças". É cinismo. Sou cínico, não há dúvida. Mas é um cinismo filosófico prático que se parece muito com a franqueza atual. As "Danças" se escreveram por si num momento de cansaço e de fraqueza. Estava exausto com a campanha de difamação que fizeram contra mim. Sofria muito. Minha inteligência começou a escrever e a dançar as "Danças". Em meia hora verdadeiramente aconsciente, estavam escritas as "Danças", que não sei quem escreveu. Depois o trabalho de poli-las que durou meses. Que tem ali muito de mim, é certo. Revelam pra quem souber olhar um sofrimento muito doído. Não há alegria nenhuma nelas. Só o Graça, com a mania de pregar a alegria, vê alegria ali. Elas são dolorosas, perversas, um mau momento que passou, um tumor que esvaziei. (DRUMMOND, 1988, p. 29).

Há outras tantas cartas nas quais Mário faz menções ao poema em questão, seja, por exemplo, para pedir a Prudente de Morais Neto cuidado na diagramação dos versos ao estampálos nas páginas da revista Estética; seja para informar a Bandeira que pediu a Cícero Dias para ilustrar o poema; ou ainda para dizer que excluiu "Danças" de Clã do jabuti, por achar "que estavam ofissaide num livro de caráter como aquele"... Creio, entretanto, que interessa reproduzir aqui só as passagens de 
sua correspondência em que se exprime um julgamento sobre o valor do poema e sobre sua dimensão moral.

É o caso de mais esta carta endereçada a Bandeira, em 28 de março de 1931, em que relata o julgamento negativo de Milliet sobre seu poema, em contraste com o de Prudentinho:

O Sérgio Milliet não pode compreender que eu tenha publicado "Danças" que ele considera puro verbalismo e vício de técnicas futuristas, palavra que essa é a opinião dele, sujeito poeta como poucos e inteligentíssimo. Já o Pru acha que é a melhor coisa dos meus versos e tem mesmo a religiosidade de o supor intangível na primeira versão. (ANDRADE \& BANDEIRA, 2000, p. 495)

Já em carta de 21/12/1930, Bandeira havia dito que "as 'Danças' resistiram ao tempo" e que teve "enorme prazer em relê-las", comovendo-o como das primeiras vezes que as lera (ANDRADE \& BANDEIRA, 2000, p. 475). Mas é em resposta a carta acima de Mário, datada de 14/04/1931, que o autor de Libertinagem vai ser mais enfático ao desancar a crítica de Milliet e ao justificar o porquê do valor do poema:

Engraçado que ele [Milliet] desgosta das "Danças" pelos motivos que sempre me desgostaram dos poemas dele! Considerar puro verbalismo e vício de técnica as "Danças" me parece o cúmulo da insensibilidade. Naturalmente a técnica do poema está perfeitamente datada, mas isso acontece com todo o poema bem feito em qualquer tempo. A emoção das "Danças", emoção expressa com grande força e pureza, intemporalizou-a. A técnica modernista foi a matriz de gesso. Até por isso estou com o Prudentinho e considero erradas pretensiosas pedantes acadêmicas as suas correções do último texto, que quase todas alteram e enfraquecem o ritmo, elemento essencialmente expressivo no poema. (ANDRADE \& BANDEIRA, 2000, p. 499)

A avaliação positiva de Manu e Pru, entretanto, não foram persuasivas o bastante para dissuadir Mário, que acabou por repudiar o poema, em prosa e verso, como se vê na carta endereçada anos depois, em 16 de junho de 1942, a Henriqueta Lisboa, onde se refere dantescamente à selva oscura em que se perdera quando da composição dos versos:

Engraçado: se há poema terrivelmente "imoral" anti-social, desumano no meu livro é "Danças" que ninguém condena! 
6 Surupango é um jogo com dança infantil sobre o qual Mário tinha grande interesse, chegando a indagar sobre sua origem e natureza em cartas a amigos como Dantas Mota. Já “Surupango da vingança" é o nome de uma cantiga de roda, inspirada em outra cantiga francesa e muito possivelmente derivada dessa dança infantil ("Surupango da vingança / Toda gente passarão [sic] / Passar roupa, faz assim / Faz assim, faz assim, também assim...) em que as crianças imitam os trabalhos domésticos da lavadeira e da passadeira. Tornou-se, além disso, uma expressão popular, de revide, tal como a emprega, por exemplo, Pedro Nava em Balão Cativo. Utilizei essa referência para título do artigo pensando não só nessa alusão expressa nos versos, mas também com o intuito de sintetizar o grande revide que caracteriza a atitude final de Mário para com a postura ética e estética encenada no próprio poema de 1924 .
E se o pus, também pra caracterizar a "selva oscura" em que me perdi, é porque depois o repudei: "Não danço mais a dança-do-ombro, Eu reconheço que sofro". Mas "Danças, poema que não trabalhei, que saiu assim mesmo como está, me desagrada e me apequena. (ANDRADE, 1990, p. 97).

E na carta acima, trata de reproduzir literalmente os versos do poema que marca a revisão crítica ou mudança radical da atitude encenada no de 1924.

Trata-se do belo "Reconhecimento de Nêmesis", poema datado de dois anos depois de "Danças", 1926, e incluído em $A$ Costela do Grã Cão, livro concebido já sob impacto das demandas éticas e políticas dirigidas à intelectualidade nos anos 1930. A mudança radical é encenada por meio do desdobramento da subjetividade lírica, fazendo aflorar seu eu infantil no momento em que o adulto se defronta com a vileza humana.

Em "Danças", a infância é mencionada indiretamente e de passagem, no momento em que o eu afirma que era feliz quando nasceu justamente porque não pensava e já dançava e cantava o "surupango da vingança". de Nêmesis" a sua infância volta a emergir de fato na figura fantasmática do "garoto feioso" e "vulgar" que ele foi, assumindo o primeiro plano no enfrentamento encenado nos versos entre o eu adulto e essa encarnação de uma possível autenticidade primeira dele mesmo - ou de sua "sinceridade", como diz Rosenfeld no ensaio sobre o cabotinismo em Mário (ROSENFELD, 1969, p. 191).

Esse enfrentamento do eu em desavença consigo mesmo justifica a referência a Nêmesis no título. Por derivação do nome da deusa da justiça distributiva ou da vingança para quem incorreu em híbris, o termo nêmesis passou a substantivo comum, a fim de designar alguém que exige ou inflige retaliação ou, por extensão de sentido, um rival, arquiinimigo, adversário terrível e geralmente vitorioso. A mesma derivação em outras línguas modernas, como a inglesa, leva a supor que o pior inimigo de uma pessoa pode não corresponder apenas a alguém oposto, mas também, de algum modo, a alguém muito semelhante a ela. Isso explica bem a relação do eu marioandradino com sua alteridade infantil. De início, eles parecem se estranhar, ou fingir se estranhar, para em seguida se dar o reconhecimento. 
O eu adulto não se define como ser nostálgico e chega mesmo a desprezar os "saudosos do passado", pois para ele a "relembrança / porta muito raramente / nos olhos dos ocupados"... Mas toda vez que se defronta com a "malvadeza brutaça / dos indivíduos humanos, / dos humanos desta praça", o curumim que ele já foi ressurge e pousa sua mão morena no braço ou, justamente, no ombro do eu adulto. Essa ressurgência não se dá como algo compensatório ou reconfortante, e ele trata logo de dizer que o menino não tem nada de anjo da guarda. É, antes, fonte de conflito de uma subjetividade cindida, que faz despertar "a minha presença em mim"... Por causa disso, diz ainda, não "posso fugir de mim! Não posso ser como os outros!" (ANDRADE, 2013, p. 407-413).

Antes que, ao final, o eu pareça buscar, pela expulsão do menino, preservar sua unidade, num apaziguamento meio resignado, de todo modo ambivalente (cf. LAFETÁ, 1986, p. 52), ao retornar às atividades cotidianas na Lopes Chaves, o poema registra as três aparições dessa identidade primeira, preservada, em dada medida, das demandas, pressões e ameaças da socialização ou da vida pública. A tais aparições, o eu adulto responde com atitudes diversas, indo da grande alegria do reencontro à irritação que o leva, covarde e perversamente, a ensinar a "indecente dança de ombros" ao menino, que, por sua vez, não quis saber e foi-se embora. O eu adulto, então, arrepende-se e, mesmo admitindo não gostar do rapaz, não queria que ele o deixasse só. Nesse momento final, correspondendo ao presente da enunciação, o eu arrependido atesta abandonar de vez o cinismo e não-me-importismo representados pela dança-de-ombros e, redimensionando a referência contida no título do poema, reconhece que sofre:

A terceira vez é agora

E eu... não sei... não gosto dele

Mas não quero que o rapaz

Me deixe sozinho aqui.

Não danço mais dança-do-ombro!

Eu reconheço que sofro!

(ANDRADE, 2013, p. 302-303) 


\section{REFERÊNCIAS}

ANDRADE, Carlos Drummond de. A lição do amigo: cartas de Mario de Andrade a Carlos Drummond de Andrade. Rio de Janeiro: Record, 1988.

ANDRADE, Mário de. Poesias completas (org. Tatiana Longo Figueiredo e Telê Ancona Lopez). Rio de Janeiro: Nova Fronteira, 2013, 2v. . Aspectos da literatura brasileira. São Paulo: Martins, s/d.

2002. O empalhador de passarinho. Belo Horizonte: Itatiaia, Querida Henriqueta. Rio de Janeiro: José Olympio, 1990. ANDRADE, Mário de e BANDEIRA, Manuel. Correspondência (org. Marcos A. de Moraes). São Paulo: EDUSP, 2000.

CAMILO, Vagner. "No atoleiro da indecisão: Brejo das almas e as polarizações ideológicas nos anos 30". Benjamin Abdala Junior e Salete de Almeida Cara. (org.). Moderno de nascença: figurações críticas do Brasil. São Paulo: Boitempo, 2006.

CANDIDO, Antonio. "O poeta itinerante". In O discurso e a cidade. São Paulo: Duas Cidades, 1993, p. 257-278. . Resenha sobre as Poesias de Mário de Andrade. Clima $n^{o} 8$, jan. 1942, p. 72-78.

LAFETÁ, João L. 1930: o Modernismo e a crítica. São Paulo: Duas Cidades, 1974.

Figuração da intimidade: imagens na poesia de Mário de Andrade. São Paulo: Martins Fontes, 1986.

PASINI, Leandro. A apreensão do desconcerto: subjetividade e nação na poesia de Mário de Andrade. São Paulo: FFLCH/USP, 2011 (tese de doutoramento).

ROSENFELD, Anatol. "Mário e o cabotinismo". In:

Texto/contexto. São Paulo: Perspectiva, 1969, p. 185-200.

SOUZA, Rodrigues de. Remate de Males: a música de poemas amorosos de MA. São Paulo: FFLCH/USP, 2009 (tese de doutoramento). 


\section{Abstract \\ Mário de Andrade's dance with shoulders: surupango of revenge}

This article analyzes "Danças" by Mário de Andra$d e$, and the reflection the poet on the aesthetic and ethical dimensions of his verses, especially in letters addressed to friends, the first to read and discuss the poem. The change his mind about his own poem is examined in association with the doubts and conflicts experimented by poets and artists in the passage from the years 1920 to 1930.

Keywords: Mário de Andrade, poetry, "Danças", "Reconhecimento de Nêmesis", Modernism. 